\title{
Drug Accountability Reference Identifier
}

National Cancer Institute

\section{Source}

National Cancer Institute. Drug Accountability Reference Identifier. NCI Thesaurus. Code C87874.

A character or string used to name, or characterize a drug accountability reference. 